\title{
La imagen, una posibilidad en la enseñanza del lenguaje escrito
}

Artículo de revisión

Fecha de Recepción: 30 noviembre 2017.

Fecha de Aprobación: 1 abril 2018.

\author{
Erwin Rafael Blanco Rojas \\ Amanda Lucía Pérez Baracaldo \\ Pedro Alexander Sosa Gutiérrez
}

\section{Resumen}

La enseñanza de la escritura es una de las principales tareas asignadas a la escuela primaria, lo cual requiere de una reflexión constante por parte del docente para el diseño y aplicación de nuevas estrategias de enseñanza al interior del aula. Se presentan los resultados obtenidos en la fase de diagnóstico, del proyecto denominado: "La imagen, una posibilidad en la enseñanza de la escritura”. El estudio se aplicó a 29 estudiantes de la I.E. Indalecio Vásquez, 23 de ellos correspondientes al grado tercero de la Sede Libertador y 6 del grado segundo de la Sede Suaneme del Municipio de Pesca en Boyacá. El objetivo de la fase inicial del proyecto se enfocó en propiciar la escritura en niños y niñas a través de la imagen. El proceso metodológico implementado, se basó en un enfoque cualitativo, sustentado en el paradigma critico social, orientado desde la Investigación Acción en el Aula. A partir de esta, se plantearon tres etapas, en la primera se determinó la aplicación de una serie de acciones para la recolección de la información, luego se diseñó una rejilla para sistematizar la información y por último se analizó y se contrastó con las teorías que orientaron el proyecto investigativo.

Palabras Clave: Imagen, Signo, Enseñanza, Escritura

\footnotetext{
* Institución Educativa Indalecio Vásquez, Sede Suaneme - Boyacá Colombia

erwinnegro@gmail.com ** Institución Educativa Indalecio Vásquez, Sede Libertador. - Boyacá Colombia lucia161906@ hotmail.com

$* * *$ Universidad Pedagógica y Tecnológica de Colombia - Boyacá - Colombia pedro.sosa@uptc.edu.co
}

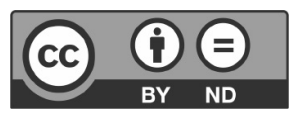




\section{Introducción}

"La imagen educa y conduce al conocimiento"

Aristóteles

Los resultados de investigación que se presentan en este documento, fueron adelantados en la Institución Educativa Indalecio Vásquez, que es uno de los tres establecimientos educativos encargados de orientar los procesos académicos a los niños y jóvenes del Municipio de Pesca. La Institución Educativa Indalecio Vásquez, es una entidad de carácter oficial, cuenta con tres (3) sedes urbanas: "Ligia Galán" que ofrece los niveles de educación básica secundaria y educación básica media; "Libertador" donde se orienta la educación básica primaria de $3^{\circ}, 4^{\circ}$ y $5^{\circ}$ y la Sede "Santander" en la cual se orienta la educación preescolar y el $1^{\circ}$ y $2^{\circ}$ de educación básica primaria, y siete (7) sedes rurales: Tobacá, José Castro, Naranjos, Llano Grande, Corazón, Herminia Galán y Suaneme, que se caracterizan por orientar los niveles de preescolar y básica primaria con la modalidad escuela multigrado. (Proyecto Educativo Institucional, 2015). Es en esta institución, en donde se originaron diferentes preguntas de investigación que buscaban entender y mejorar los aspectos que afectan el desarrollo de las actividades misionales institucionales, el desempeño de los estudiantes y el de los maestros.

Los aspectos que suscitaron las preguntas de investigación para el desarrollo de este proyecto tienen relación con el desempeño en las pruebas estandarizadas nacionales de los estudiantes en la I.E Indalecio Vásquez. Al revisar el Índice Sintético de Calidad Educativa y las pruebas SABER en los años 2015 y 2016, se encontró que en tercer grado $\left(3^{\circ}\right)$ los estudiantes de la Institución Educativa Indalecio Vásquez "en comparación con los establecimientos educativos que presentan puntajes promedio similares, en el área y grado evaluado, el establecimiento es débil en la competencia Comunicativa-escritora y en el componente Pragmático". (figuras 1 y 2) (ICFES Resultados Pruebas SABER 2015, 2016).

\section{Resultados de tercer grado en el área de lenguaje}

촐
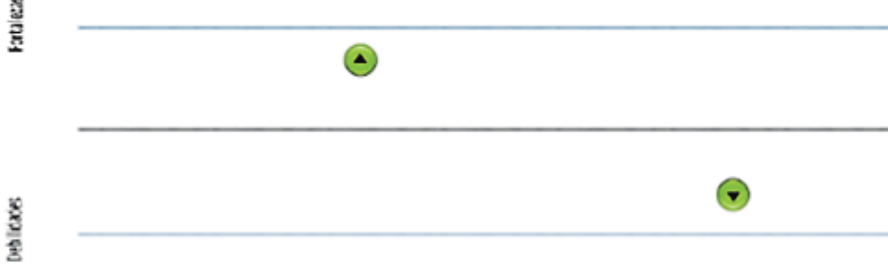

Comunicatwa-lectora
Figura. 1 Resultados

Competencias Lenguaje Tercer Grado Institución Educativa Indalecio Vásquez Pruebas SABER 2015. Fuente: ICFES (2015) 
Figura. 2 Resultados Componentes Lenguaje Tercer Grado Institución Educativa Indalecio Vásquez Pruebas SABER 2015. Fuente: ICFES (2015)

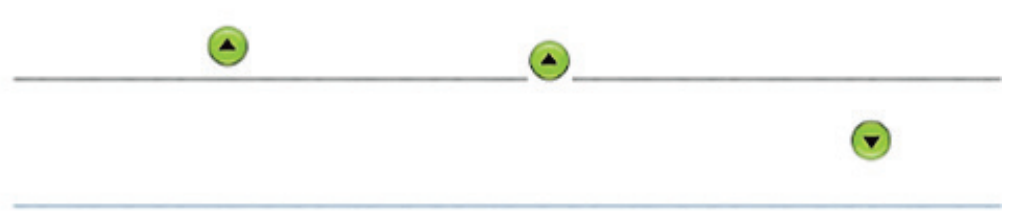

\begin{tabular}{lll}
\hline Semántico & Sintáctico & Progmático
\end{tabular}

Para el caso de los resultados SABER de quinto grado $\left(5^{\circ}\right)$ en el área de Lenguaje, la Institución Educativa Indalecio Vásquez "en comparación con los establecimientos educativos que presentan puntajes promedio similares, en el área y grado evaluado, es similar en la Competencia Comunicativaescritora, pero débil en el componente Pragmático" (figuras 3 y 4) (ICFES Resultados Pruebas SABER 2015, 2016)

Figura 3. Resultados Competencias Lenguaje Quinto Grado Institución Educativa Indalecio Vásquez Pruebas SABER 2015. Fuente: ICFES (2015)

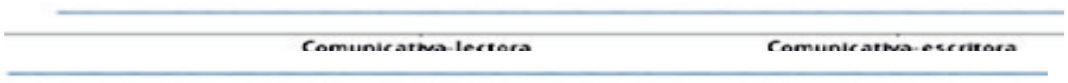

Figura 4. Resultados Componentes Lenguaje Quinto Grado Institución Educativa Indalecio Vásquez Pruebas SABER 2015. Fuente: ICFES (2015)

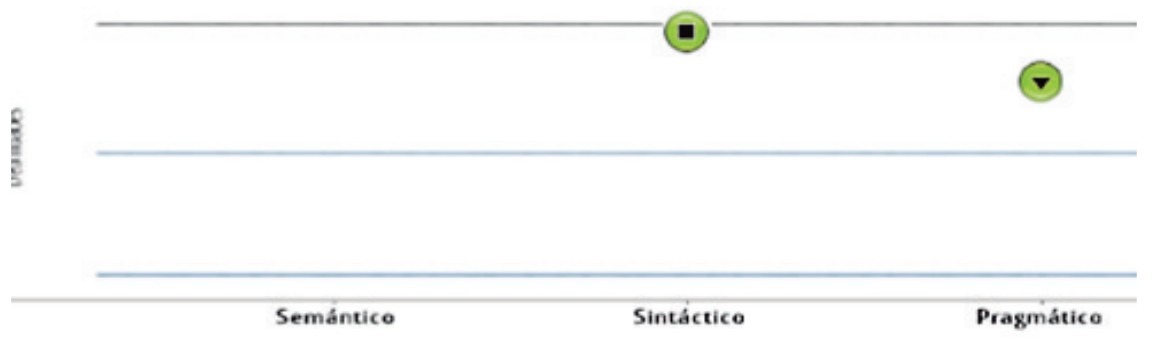


Basados en estos resultados, surgió la preocupación por mejorar la enseñanza de la escritura buscando privilegiar el componente pragmático. En ese sentido, se buscó involucrar actividades diferentes a las convencionales, y usadas continuamente en la enseñanza de la producción escrita, que sirviesen como aporte didáctico a la comunidad educativa de la institución para el fortalecimiento de dicha competencia, y a su vez orientar al niño hacia el dominio del lenguaje escrito. Para atender a dicha debilidad, encontramos que la imagen a tenido una estrecha relación con la educación, ha sido desde tiempos remotos una gran posibilidad en la enseñanza del lenguaje escrito, ya que está relacionada con el mundo en el que vivimos creándolo, representándolo y animándolo, de la misma forma "es algo cotidiano que nos rodea y con lo que entramos en contacto todos los días de nuestra vida" (Acaso M, 2009, p. 19). Es por esto que nace la pregunta de investigación ¿Cómo la imagen propicia la escritura en los estudiantes de $2^{\circ}$ de la Sede Suaneme y $3^{\circ} \mathrm{A}$ de la sede Libertador en la Institución Educativa Indalecio Vásquez del municipio de Pesca, Boyacá?

A partir de estos presupuestos, surge la iniciativa de establecer la propuesta de intervención didáctica: La imagen, una posibilidad en la enseñanza del lenguaje escrito, para lo cual se determinó: Propiciar la escritura a través de la imagen, caracterizando las fortalezas y debilidades en la escritura de los estudiantes, a través de la aplicación de una serie de actividades orientadas desde el material diseñado por el Programa "Todos a Aprender", del Ministerio de Educación Nacional, luego se diseñó una rejilla para el análisis de los resultados obtenidos, contrastando y sistematizando los mismos con las categorías para el análisis de producción textual propuestos por el Ministerio de Educación Nacional.

De esta forma, al relacionar la imagen con la producción textual se busca que los niños involucren elementos cotidianos, fantasías, relatos, objetos, imágenes, cuentos, anécdotas, entre otros elementos, pasando de una actividad verbal, a una producción escritural. En el mismo sentido que Cassany (1999) delimita la idea de escritura "[...] como una manifestación de la actividad lingüística humana que comparte los rasgos de intencionalidad y de contextualización de la actividad verbal“" (p. 112),

\section{Metodología}

De acuerdo con la naturaleza del problema, y que esté se encuentra centrado en el quehacer pedagógico en el aula de clase. La mejor forma de abordarlo es desde un enfoque cualitativo, teniendo en cuenta el paradigma critico social. De esta manera se reivindica "el estudio de la vida cotidiana como el escenario básico de construcción, constitución y desarrollo de los distintos planos que configuran e integran las dimensiones específicas del mundo humano", (Sandoval, 1996, p. 15). En este sentido, los momentos por los que pasa el desarrollo de esta propuesta de 
intervención son: los de "formulación, diseño, gestión y cierre. A través de ellos, es posible trascender la mera descripción, permitiendo el acceso a formulaciones de tipo comprensivo en algunos casos, y explicativas en otros”. (Sandoval, 1996, p. 29).

Esta propuesta se ubica en un enfoque cualitativo, se debe aclarar que fue mediada por el paradigma critico social, teniendo en cuenta que la práctica pedagógica en el aula establece relaciones entre estudiantes y profesor, "asumiendo que el conocimiento es una creación compartida a partir de la interacción entre el investigador y el investigado, en la cual, los valores median o influyen en la generación del conocimiento; lo que hace necesario "meterse en la realidad"(Sandoval, 1996, p. 29). Esta relación entre docente y estudiante, que se constituye a manera de relevos, permite vincular la Investigación Acción en el Aula, como el tipo de investigación que reúne las condiciones establecidas por Elliot Eisner (2005) "La investigaciónacción se relaciona con los problemas prácticos cotidianos experimentados por los profesores, en vez de con los "problemas teóricos" definidos por los investigadores puros en el entorno de una disciplina del saber” (p. 24).

De acuerdo con los instrumentos seleccionados y lo anteriormente descrito, se tendrán en cuenta las propuestas y referidas por Suárez, (2002), "las notas de campo, diarios de docentes y estudiantes," (p. 45) [...] [...] "registros y pruebas de rendimiento de los alumnos. (Hopkins, 1989; Winter,
1989, Referidos por: Suárez, 2002, p. 42).

Considerando la asignación académica de los docentes que intervienen en la presente propuesta, se escogió como población participante, veintisiete (27) estudiantes, distribuidos de la siguiente manera: 21 estudiantes de tercer grado $\left(3^{\circ}\right)$ de la Sede Libertador con edades entre los 8 y los 9 años de edad y seis (6) estudiantes segundo $\left(2^{\circ}\right)$ de la Sede Suaneme, con una edad promedio de 7 años, a su vez, es relevante mencionar que los estudiantes de $3^{\circ} \mathrm{A}$ presentaron este año sus pruebas nacionales lo cual nos servirá como insumo para analizar sus debilidades y fortalezas, y los estudiantes de segundo grado.

\section{La imagen en la enseñanza del lenguaje escrito.}

El uso de la imagen en la enseñanza no es un asunto innovador del todo, en una revisión preliminar de los trabajos que han referido la utilización de la imagen en la escuela, se halló que son diversos los autores que han hecho desarrollos en este aspecto. Por lo tanto, es conveniente señalar algunos trabajos destacados que sirven de apoyo al presente proceso. En este sentido Enrique Llorente Cámara, de la Universidad del País Vasco, ha publicado en la revista Psicodidáctica, artículos como: "Imágenes en la enseñanza” año 2000, p. 119 - 135; "Medios visuales y Educación visual" año 1998, p. 69 - 82; y otros en los cuales ha sido coautor y/o colaborador como "Las imágenes en los libros de texto de ciencias. Un estudio en la educación primaria" año 1997, p. 121 a 143; "Las imágenes en la enseñanza - 
"Expresar con el lenguaje audiovisual comporta dominar [...] [...] la creación de historias y la narración mediante imágenes. Se trata de aprender a describir un mundo coherente y verosímil, unos personajes con sus intenciones $\mathrm{y}$ las acciones que luego se traducen en el argumento. $\mathrm{Y}$, al mismo tiempo, es necesario conocer las normas básicas del lenguaje de la imagen y los procesos de secuenciación de la narrativa audiovisual" aprendizaje de la biología” año 1998, p. 45 - 54; en los cuales se evidencia la estrecha relación que históricamente ha tenido la imagen con la enseñanza de las artes plásticas y las ciencias.

Del mismo modo, el artículo: "Aprender y enseñar a través de imágenes. Desafío educativo” en el año 2014, de Daiana Yamila Rigo de la Universidad Nacional de Río Cuarto Argentina, publicado en la revista española ASRI Arte y Sociedad. Revista de Investigación, "muestra la experiencia de la puesta en práctica de un diseño instructivo definido a partir del uso de recursos educativos icónicos con el objetivo de conocer cómo los alumnos valoran la realización de actividades académicas definidas a partir de imágenes, fotografías y obras de arte.” (Rigo, 2014, p. 6).

En otros trabajos realizados en el tema de estudio, los autores se refieren más específicamente a estrategias de enseñanza que directamente tiene relación con la imagen sin que sea tomada de una forma general, sino por el contrario de una manera más específica, en este sentido se reconocen los trabajos realizados por Blas Segovia Aguilar, quien es coordinador de Aula de Mejora Educativa de La Universidad de Córdoba y de la Sub Red Andaluza Universitaria de Comunidades de Aprendizaje. Dentro de las múltiples publicaciones de Blas Segovia Aguilar es preciso mencionar: "Desarrollo de la narrativa visual de los escolares con el cómic” año 2010, "La adquisición de la competencia narrativa a través del cómic en la Escuela Primaria" año
2012; trabajos de los cuales el mismo autor concluye:

"Expresar con el lenguaje audiovisual comporta dominar [...] [...] la creación de historias y la narración mediante imágenes. Se trata de aprender a describir un mundo coherente y verosímil, unos personajes con sus intenciones y las acciones que luego se traducen en el argumento. Y, al mismo tiempo, es necesario conocer las normas básicas del lenguaje de la imagen y los procesos de secuenciación de la narrativa audiovisual" (Segovia, 2012).

En Colombia también se han realizados diversos trabajos investigativos relacionados con la utilización de la imagen en el campo de la enseñanza, es así como: Katherine Juliet Rojas Hurtado y José del Carmen Tejada Rentería, estudiantes de la Maestría Comunicación Educación de la Universidad Distrital Francisco José de Caldas, en su trabajo de grado "El Cómic un lugar para la narración del mundo de los niños y niñas” año 2015, presenta dentro de sus conclusiones, que a través del cómic se evidencia un fortalecimiento de las habilidades comunicativas como la escritura y la lectura desde su comprensión y producción. (Rojas \& Tejada, 2015 p. 76).

\section{La enseñanza de la escritura}

Con relación a la enseñanza de la escritura, son diversos los autores y publicaciones. Sin embargo, se retomarán solo algunas de las publicaciones más significativas que 
sirvieron como apoyo a la propuesta de intervención desarrollada. En este sentido, es importante resaltar la publicación realizada por Olga Valery de la Facultad de Humanidades de la Universidad de los Andes de Mérida, Venezuela, quien en su artículo "Reflexiones de la escritura a partir de Vigosky", publicado en la Revista Venezolana de Educación EDUCARE, en el año 2000, concluye que "la acción del docente durante el proceso de adquisición de la escritura, tiene la característica de una participación activa, capaz de conducir al estudiante a vivir y a experimentar el proceso de composición escrita con todas sus dificultades y gratificaciones, a comprenderlo y a tomar consciencia del proceso" (Valery, 2000, p. 38-43)

Del mismo modo, los docentes del Colegio Público "Juan Bautista Irurzun" de Peralta España, desarrollaron una interesante propuesta de intervención didáctica, titulada "El aprendizaje del lenguaje escrito Infantil” quienes orientados por Myriam Nemirovsky, concluyen que el niño aprehende de la realidad cercana al interactuar con ella y así aumenta la autoestima y la curiosidad, para, en definitiva, tratar de crear unos lectores y escritores competentes y autónomos. (Amatriain et al, 2004 p. 81)

Por supuesto en el contexto nacional también se encuentran diversos trabajos enfocados a la lectura y escritura, sin embargo, llama la atención la propuesta "Escribamos el Arte", de los docentes: Carlos Alfonso Serrano Acostal y Nidia Gineth Acevedo Contreras, desarrollado con estudiantes del grado $8^{\circ}$ del Colegio Atenas IED de Santa Fé de Bogotá, y publicado en el libro "La lectura y la escritura como procesos transversales en la escuela. Experiencias innovadoras en Bogotá" en el año 2009. En la mencionada publicación, se resaltan la implementación "del uso de los medios audiovisuales, no solo como medio de enseñanza para hacerla más comprensible y aceptable (películas, videos, música) sino también como medio de producción artística y textual (imágenes, pósters, películas caseras, entre otros), permitiéndole a los (as) estudiantes, aprender significativamente" (Serrano \& Acevedo, 2009, p. 215).

\section{La imagen en la historia de la enseñanza}

Para abordar los referentes teóricos de la propuesta de intervención: La imagen. Una posibilidad en la enseñanza del lenguaje escrito, iniciaremos describiendo los antecedentes históricos, posteriormente se contextualizan los elementos teóricos y conceptuales que son determinantes en la formulación del la propuesta, en este sentido se inicia por hacer un breve recuento relacionado con la incidencia que la imagen ha tenido desde la era paleolítica hasta la edad moderna y su relación con la enseñanza en la escuela, además de la revisión de otros conceptos como imagen, signo y enseñanza de la escritura, para lo cual se tienen en cuenta autores como: (Perelllo, 1986); (Joly, 2009); (Aguirre, 2001); (Guiraud P, 2004); (Saussure, 1949); (Pierce, 1974); (Ferreiro \& Teberosky, 1991). 
Existe una estrecha relación entre el hombre, y la forma como él aprende el mundo. Esta relación esta dada por elementos casi olvidados en la cultura, como pueden ser las imágenes. Coloquialmente se escucha con mucha frecuencia el refrán: "Una Imagen vale más que mil palabras", tal vez si, o tal vez no, sin embargo, esta frase puede convertirse en la excusa para entender los fenómenos de aprendizaje escolar. En este sentido, las evidencias históricas y hallazgos como el arte rupestre de la era paleolítica, demuestran que el hombre de esta época "era capaz de sustituir la simple imitación de la realidad por modelos expresados en formas simbólicas" (Perello, 1986), estas imágenes grabadas en las paredes de los abrigos rocosos en los que se refugiaban estos "hombres de las Cavernas”, demostraría que el hombre siempre ha tenido la necesidad de utilizar la imagen con diversos fines $\mathrm{y}$ ha generado diferentes preguntas antropológicas y pedagógicas entre ellas: ¿es posible que uno de los objetivos de las imágenes en el arte rupestre fuera el didáctico?. Si la respuesta a esta inquietud se estableciera como positiva probablemente encontraríamos la primera evidencia de la utilización de la imagen con el fin de enseñar. (figura 5).

Así mismo "estos dibujos estaban destinados a comunicar mensajes y muchos de ellos constituyeron lo que se puede entender como "precursores de la escritura", utilizando procesos de "descripción-representación" que contenían solo un desarrollo esquemático de la representación de las cosas reales” (Joly, 2009, p. 21)

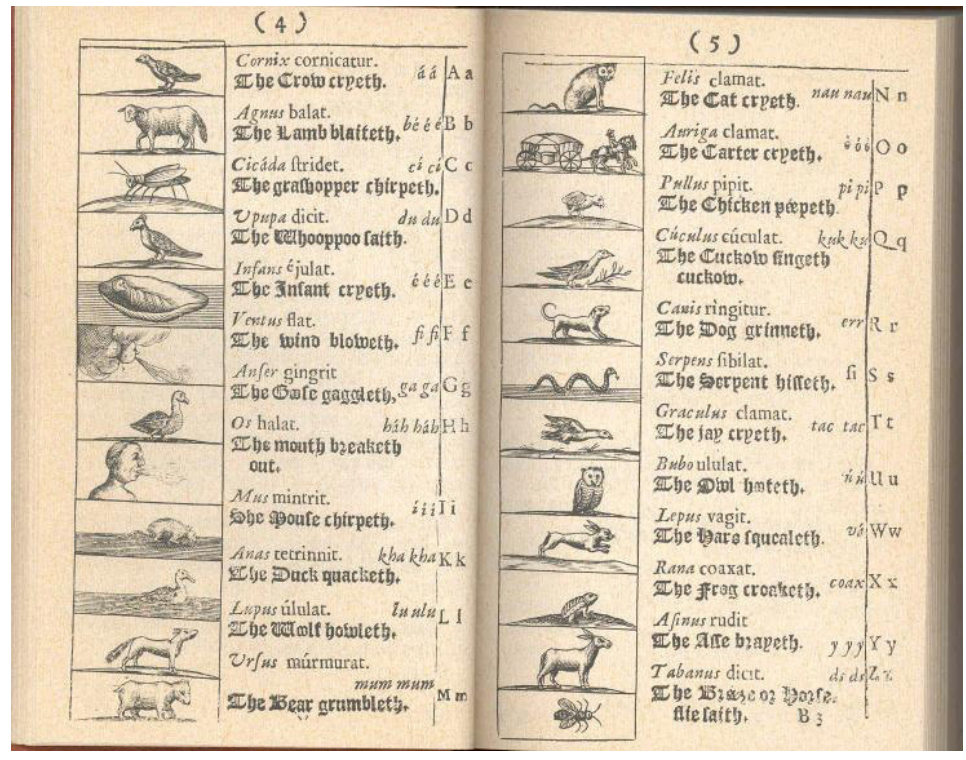

Figura 5. Arte rupestre era paleolítica. Fuente: palmeralfotografias.blogspot.nl

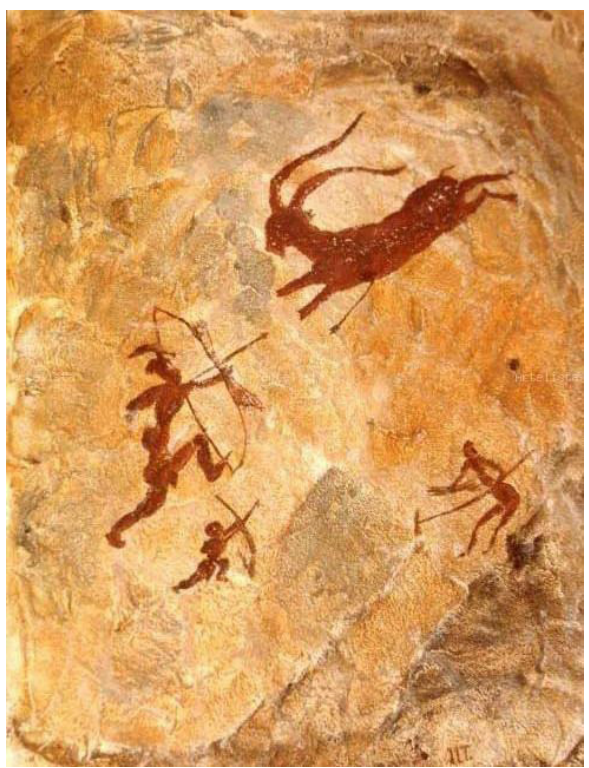

Figura 6. Enseñanza con imágenes. Fuente: Orbis Sensalium Pictus (1659) 
Sintetizando el origen del termino "imagen" descrito por Joly (2009) quien señala que ésta, proviene del latín imago para designar la máscara mortuoria que se vestía en los funerales de la antigua roma, para Platón la imagen engaña, desvía de la verdad, mientras para Aristóteles, la imagen educa y conduce al conocimiento ( $\mathrm{p}$. $22-23)$.

En este mismo sentido y retomando la posición Aristotélica en la cual la imagen educa y conduce al conocimiento, se podría asegurar que la utilización de la misma en el proceso de enseñanza no es algo nuevo, constituyéndose como una innovación en la enseñanza desde la aparición del Orbis Sensualium Pictus, obra realizada en el año 1659 por el famoso pedagogo Juan Amos Comenio, quien inspirado en el pensamiento enciclopedista de la época a utilizando la imagen como estrategia para conocer el mundo se "organiza en ciento cincuenta y dos capítulos que dan cuenta de la organización del conocimiento y de la percepción de la realidad de los hombres del siglo XVII, de una manera total" (Aguirre, 2001, p. 7 ) (figura 6)

Lejos de lo innovador que fue para Comenio en el Orbis, y para Diderot en la enciclopedia. La imagen es hoy, un elemento cotidiano. Se puede decir que hoy mas que nunca en la historia del hombre el "analfabetismo" esta relacionado con las formas de producción y lectura de la imagen ya que este se convirtió en un elemento inmanente a la cotidianidad de nuestra época.
Es así como se pude establecer que, "El concepto de imagen comprende otros ámbitos que van más allá de los productos de la comunicación visual y del arte; implica también procesos como el pensamiento, la percepción, la memoria, en suma, la conducta. Es, por tanto, un concepto más amplio que el de representación icónica” (Villafañe, 1985, p. 29). Del mismo modo, se puede agregar que la imagen esta "relacionada con el signo y el símbolo, con la imaginación, se ha definido como una representación, copia o analogía, según Sartre quien luego se pregunta: “¿Es aprendizaje o saber?" es saber porque la imagen no se aprende" (Calderón, 2009, p. 19).

Teniendo en cuenta las anteriores consideraciones, y la relación que tiene para este proyecto la imagen y la escritura. Identificamos un elemento común en las dos: el signo, elemento que se constituye en posibilidad para la escritura ya que el signo es en las dos la unidad mas pequeña de significación que permitirá la producción textual y el pensamiento.

\section{La Escritura}

Siguiendo con el abordaje del tema que nos ocupa sobre la propuesta de intervención didáctica en las Sedes Libertador y Suaneme de la I.E Indalecio Vásquez, se revisaran los aportes más significativos relacionados con el proceso de escritura en los estudiantes, teniendo en cuanta las concepciones sobre imagen, escritura y enseñanza de la escritura. El significado que para el presente trabajo se le da al
El concepto de imagen comprende otros ámbitos que van más allá de los productos de la comunicación visual y del arte; implica también procesos como el pensamiento, la percepción, la memoria, en suma, la conducta. Es, por tanto, un concepto más amplio que el de representación icónica 
proceso de enseñanza de la escritura, entendiéndose el mismo como "el camino que el niño debe recorrer para comprender las características, el valor y la función de la escritura, desde que esta se constituye en objeto de su atención (y por tanto de su conocimiento)" ((Ferreiro \& Teberosky, 1991, p. 9).

Con respecto a la escritura Ferreiro (1997) considera que "puede ser conceptualizada de dos maneras muy diferentes, y según sea el modo en que se la considere, las consecuencias pedagógicas difieren drásticamente. La escritura puede ser considerada como una representación del lenguaje oral o como un código de transcripción gráfico de las unidades sonoras en unidades gráficas.... (p. 13).
En este sentido Ferreiro (1997) determina que "si la escritura se concibe como un código de transcripción, su aprendizaje se concibe como la adquisición de una técnica; si la escritura se concibe como un sistema de representación, su aprendizaje se convierte en la apropiación de un nuevo objeto de conocimiento, o sea, en un aprendizaje conceptual. (p. 17).

De esta manera el Ministerio de Educación Nacional (1998), basado en los planteamientos de Ferreiro \& Teberosky (1997), orienta a los docentes a través de los lineamientos curriculares para el área de lenguaje, concentrado esta teoría en los siguientes niveles del desarrollo de la escritura en los niños (Figura 7)

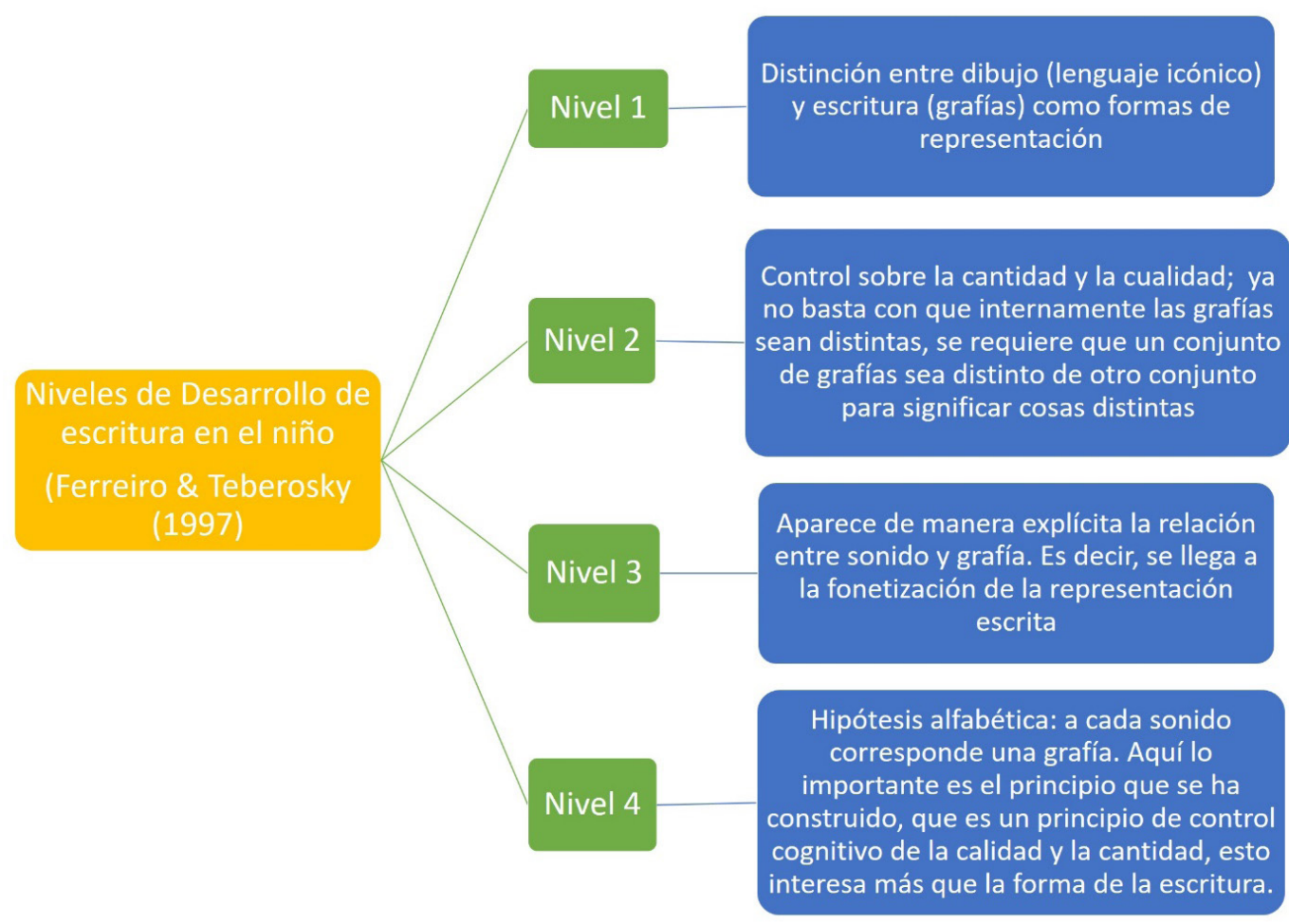

Figura 7. Niveles de Desarrollo de escritura en el niño. Fuente: MEN (1998) 
De aquí en adelante el reto es avanzar en la construcción de los demás principios complejos del sistema de escritura: la sintaxis, la segmentación semántica de unidades, las reglas ortográficas. Podríamos decir que, por esta razón, a nivel didáctico, este enfoque es más complejo que uno que comience el proceso de acercamiento a la lengua escrita desde la fonetización: letras... sílabas... combinaciones... palabras... El asunto es comprender que, en la marcha natural de construcción de la lengua escrita por el niño, la fonetización es punto de llegada y no de partida. Y que ésta ha sido la historia cultural filogenética de la escritura. (MEN, 1998, p. 57 - 59)
Por otro lado, para el análisis de la producción escrita, el Ministerio de Educación Nacional, propone cuatro niveles, que se sintetizan en la gráfica 7. Estos niveles nos permitieron describir con claridad los aspectos mas relevantes en el desempeño de los estudiantes, y apoyados por Ferreiro \&Teberosky quienes complementaron la caracterización y el diseño de la estrategia de intervención.

\section{Corolarios}

A continuación, se presenta la síntesis del análisis de los textos escritos por los niños y niñas de segundo grado de la Sede Suaneme y Grado
- Producir más de una proposición de manera coherente proposición.

- Seguir un hilo temático a lo largo del texto

sujeto/verbo.

- Segmentar o delimitar debidamente la proposición.

Nivel A

Coherencia y Cohesión Local

- La intención (intencionalidad del enunciado presentado)

- Establece algún tipo de - La superestructura (Se relación estructural entre selecciona y se controla un las proposiciones. tipo de texto en sus componentes globales: texto descriptivo, texto narrativo, texto enumerativo interproposicional/es a través del uso de signos de puntuación con función lógica

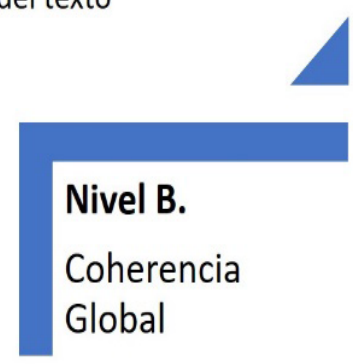

Nivel C.

Coherencia y Cohesión Lineal
Nivel D.

Pragmática

Figura 7. Niveles de Análisis de la producción escrita. Fuente: MEN (1998) 
tercero A de la Sede Libertador que corresponde a una primera fase del proyecto de intervención didáctica que consistía en: caracterizar las fortalezas y debilidades en la escritura en este grupo de estudiantes, para esta etapa se selecciono una de las actividades académicas cotidianas en la clase de lenguaje, tomada del cuaderno de trabajo del estudiante "entre textos", suministrado por el Ministerio de Educación Nacional, a través del Programa Todos a Aprender

\begin{tabular}{|c|c|c|}
\hline ESCRITURA & SI & NO \\
\hline ORTOGRAFÍA & & \\
\hline Acentúa debidamente las palabras con tildes & 21 & 8 \\
\hline Confusión o mala utilización de grafías y/o fonemas(b-v;s-z-c, g -j; r-rr, k-q; i -y) & 23 & 6 \\
\hline Cambia las grafías (lateralidad) (d-b; p-q) & 2 & 26 \\
\hline otro: ( & 3 & 0 \\
\hline SEGMENTACIÓN DE PALABRAS & SI & NO \\
\hline Segmenta adecuadamente las palabras (separa una palabra de otra) & 13 & 16 \\
\hline Segmenta adecuadamente las palabras (No separa las palabras por sílabas) & 19 & 10 \\
\hline SUPRESIÓN & SI & NO \\
\hline Suprime grafías & 9 & 20 \\
\hline Suprime sílabas & 1 & 27 \\
\hline otro: Agrega grafías y/o sílabas & 1 & 1 \\
\hline
\end{tabular}

Figura 8. Análisis de la Escritura de los participantes. Fuente: Autores

En este sentido, en la figura 8, se observa que la gran mayoría de los estudiantes de los grados segundo y tercero A de las sedes Suaneme y Libertador, respectivamente, se ubican en el nivel 4 de escritura, correspondiente a "la hipótesis alfabética: a cada sonido corresponde una grafía”, donde lo que interesa es el control cognitivo de cantidad y calidad más que la forma de la escritura" (MEN, 1998 p. 59),sin embargo, Un estudiante de $3^{\circ}$ A de la Sede Libertador, se encuentran en el Nivel 3 de desarrollo de la escritura ya que aunque llega a la "fonetización de la representación escrita" lo cual se refiere a que "Se ha trabajado la necesidad de simbolizar, a través de representaciones gráficas (letras), un significado o una realidad, sin embargo no alcanza a desarrollar la "hipótesis alfabética”(Ferreriro y Teberosky, 1997. Referido por el MEN, 1998)

En este mismo sentido, referente a la forma de la escritura, se evidencian debilidades en cuanto a su escritura relacionadas con la ortografía (acentuación de palabras con la tilde, uso de la "h", "b", "v", "k", “r", "s" y “z”), y en muy pocos casos, (solo dos) existen problemas de lateralidad ( $\mathrm{p}$ - 
q, b-d) de igual manera menos de la mitad de los estudiantes segmentan adecuadamente las palabras en cuanto se refiere a que se deje un espacio entre una palabra y otra, y una mayoría que corresponde a más de la mitad de los estudiantes separa algunas palabras por silabas, a su vez una tercera parte de los estudiantes suprime algunas grafías en las palabras y un solo estudiante suprime silabas en las palabras.

\begin{tabular}{|c|c|c|}
\hline CATEGORÍAS DE ANÁLISIS & SI & NO \\
\hline NIVEL A - Coherencia y cohesión local & & \\
\hline Producir al menos una proposición & 29 & \\
\hline Contar con concordancia sujeto/verbo & 25 & 4 \\
\hline Segmentar o delimitar debidamente la proposición & 27 & 2 \\
\hline NIVEL B - Coherencia global & SI & NO \\
\hline Producir más de una proposición de manera coherente & 9 & 20 \\
\hline Seguir un hilo temático a lo largo del texto & 10 & 19 \\
\hline NIVEL C - Coherencia y Cohesión lineal & SI & NO \\
\hline Establece algún tipo de relación estructural entre las proposiciones & 8 & 21 \\
\hline $\begin{array}{c}\text { Evidencia la/s relación/es interproposicional/es a través del uso de signos de } \\
\text { puntación con función lógica }\end{array}$ & 0 & 29 \\
\hline NIVEL D-Pragmática & SI & NO \\
\hline La Intención del enunciado presentado & 25 & 4 \\
\hline $\begin{array}{c}\text { La Superestructura (se selecciona y se controla un tipo de texto en sus } \\
\text { componentes globales: (texto descriptivo, narrativo, informativo) }\end{array}$ & 1 & 28 \\
\hline
\end{tabular}

Figura 9. Niveles de Análisis de la producción escrita propuestos por el MEN (1998). Fuente: autores

En la figura 9, se evidencian fortalezas en la producción textual, ya que la totalidad de los estudiantes componen por lo menos una proposición, y la gran mayoría equivalente a más de las tres cuartas partes de los estudiantes, segmenta las proposiciones por lo menos con espacios en blanco y cuentan con concordancia sujeto/verbo, lo cual corresponde a el nivel A referente a la coherencia y cohesión local propuesto por el MEN (1998).
A su vez, solo una tercera parte de los estudiantes logran "producir más de una proposición de manera coherente" y "seguir un hilo temático a lo largo del texto" correspondiente al nivel B propuesto por el MEN (1998), de igual manera, menos de una tercera parte de los estudiantes participantes en esta investigación, establecen "algún tipo de relación estructural entre proposiciones" y ninguno "evidencia la relación interproposicional a través del uso de 
Los resultados de la caracterización de la producción textual de los estudiantes demuestra la necesidad de hacer uso de diferentes estrategias buscando mejorar los aspectos identificados en las pruebas saber signos de puntuación con función lógica", lo cual se convierte en una oportunidad para el mejoramiento de la producción textual en los estudiantes y de este modo lograr ubicar a los estudiantes en el nivel C propuesto por el MEN (1998).

En cuanto se refiere al nivel D. correspondiente a la Pragmática se evidencia una debilidad mayor lo cual evidencia el análisis realizado en las pruebas saber 2015, la gran mayoría de los estudiantes aunque tiene claro la intencionalidad del texto que escriben, no logran desarrollar "la superestructura" es decir que no tienen claro los componentes globales del tipo de texto que desean escribir, para nuestro análisis, un texto descriptivo en el segundo grado de la sede Suaneme y un texto narrativo en el tercer grado de la sede Libertador.

\section{Conclusiones}

Con estos presupuestos teóricos y diagnósticos, se desarrolló una serie de actividades de intervención en donde los niños experimentaron frente a su percepción de mundo y a las posibilidades de construir nuevos relatos. Entre las actividades se busco establecer relaciones entre la escritura, la imagen y la imaginación. De esta manera el ejercicio de la enseñanza de la escritura se convirtió en un ejercicio de creación.

La matriz diseñada por el grupo de investigadores, es una herramienta que facilitó la sistematización y análisis tanto de la forma como escriben los estudiantes como la sistematización y análisis de las categorías de producción textual. De los ejercicios de escritura que realizan los estudiantes en el aula se puede obtener información muy valiosa que, al ser sistematizada, analizada y contrastada con las teorías planteadas, generan propuestas que pueden mejorar las prácticas en el aula y de esta manera contribuir al mejoramiento de la vida académica de nuestros estudiantes.

La propuesta de intervención didáctica ha generado diversas reflexiones, análisis y profundización en lo que se refiere a la labor como docente, principalmente, sobre la importancia de la investigación en el aula como una de las mejores estrategias para lograr cambios significativos en la práctica pedagógica y el mejoramiento de la calidad educativa.

Los resultados de la caracterización de la producción textual de los estudiantes demuestra la necesidad de hacer uso de diferentes estrategias buscando mejorar los aspectos identificados en las pruebas saber. La imagen según lo presentado se convierte en una interesante posibilidad teniendo en cuenta la cercanía que tienen los estudiantes frente a esta y las contingencias que brinda en la interacción escolar.

En la actualidad, las actividades escolares de enseñanza, tienen retos permanentes para el maestro. Estos desafios deben involucrar elementos, objetos y temas de la cotidianidad de los niños, en donde ellos puedan construir nuevas relaciones frente al conocimiento. La imagen, es para el desarrollo de este proyecto, ese elemento que permite a los niños involucrarse con la escritura de manera lúdica y espontanea relacionando su experiencia de mundo con la escritura y la creación. 


\section{Referencias Bibliográficas}

Aguirre, Ma. E. (2001). Enseñar con textos e imágenes. Una de las aportaciones de Juan AMÓS Comenio. Revista Electrónica de Investigación Educativa.

Aguilar, B. S. (2010). Desarrollo de la narrativa visual de los escolares con el cómic. Revista Iberoamericana de Educación, 51(5), 7.

Calderón, H. (2009). Introducción al Conocimiento de la Imagen. México, DF: Siglo XXI Editores.

Cámara, E. L. (2000). Imágenes en la enseñanza. Revista de Psicodidáctica, 119.

Cassany, D. (1999). Construir la escritura. Barcelona. Paidos. Madrid.

Ferreiro, E., \&Teberosky, A. (1991). Los sistemas de escritura en el desarrollo del niño. siglo xxi.

Guiraud, P. (1979). La semiología. Siglo XXI.

Institución Educativa Indalecio Vásquez (2015). Proyecto Educativo Institucional.

Lerner, D. (2004). Leer y escribir en la escuela. Lo real, lo posible y lo necesario. México: FCE/SEP.

Llorente, E. (1998). Medios visuales y educación visual. Revista de Psicodidáctica, (5), 69-82.

Ministerio de Educación Nacional (1998). Lengua castellana lineamientos curriculares. Santa Fé de Bogotá. Cooperativa editorial magisterio.

Ministerio de Educación Nacional (2015). Centro virtual de noticias de educación.

Ministerio de Educación Nacional (2016). Estándares básicos de competencias, revolución

Rigo, D. Y. (2014). Aprender y enseñar a través de imágenes: desafío educativo. ASRI: Arte y sociedad. Revista de investigación, 6(6).

Sandoval C. (1996). Programa de Especialización en Teoría, Métodos y técnicas de investigación Social, Investigación Cualitativa. ICFES. Bogotá Colombia.

Segovia, B. (2012). La adquisición de la competencia narrativa a través del cómic en la Escuela Primaria.

Serrano, C. \& Acevedo, N. (2009). Escribamos el Arte. La lectura y la escritura como procesos transversales en la escuela. Experiencias innovadoras en 
Bogotá. Instituto para la Investigación Educativa y el Desarrollo Pedagógico, IDEP, pp. 207 - 219.

Suárez, M. (2002). Algunas reflexiones sobre la investigación-acción colaboradora en la educación.

Tejada, J., \& Rojas, J. (2015). El cómic: Un lugar para la narración del mundo de los niños y las niñas.

Valery, O. (2000). Reflexiones sobre la escritura a partir de Vygostky. Educere,3(9), 3843.

Villafañe, J. (1985). Introducción a la teoría de la imagen. Pirámide. 